\title{
FEATURES OF CORPORATE WELL-BEING
}

\section{Iryna Burlakova ${ }^{1}$, Oleksiy Sheviakov ${ }^{2}$, Tetiana Kondes ${ }^{3}$}

${ }^{I}$ Doctor of Sciences (Psychology), Associate professor, East-Ukrainian National University named after Volodymyr Dahl, professor of the Department of Practical Psychology and Social Work, Severodonetsk, Ukraine, email: burlakova22irina@gmail.com, ORCID: orcid.org/0000-0002-6043-4359

${ }^{2}$ Doctor of Sciences (Psychology), Professor, Private Higher Educational Establishment «Dnipro Humanitarian University», Head of the Department of General Psychology, Dnipro, Ukraine, email: shevyakovy0@gmail.com,ORCID: orcid.org/0000-0001-8348-1935

${ }^{3}$ Ph.D. (Psychology), "KROK" University, Associate Professor of the Foreign Languages and General Educational Disciplines Department, Kyiv, Ukraine, email: tetianakv@krok.edu.ua, ORCID: orcid.org/0000-0001-8514-9389

One of the important areas of future wellbeing programs in corporations will be the creation of a positive and healthy workplace culture. This will help maintain healthy staff habits both in and out of the office. Only $10 \%$ of health is determined by medical care. $90 \%$ - by lifestyle choices, genetics and social determinants. Wellbeing brings together mental health (mind) and physical health (body), resulting in more holistic approaches to disease prevention and health promotion. Many companies are already approaching such spending as an investment in human capital. After all, investing in people's mental health affects employee turnover, productivity, company culture. Our sociological survey made it possible to determine what is wellbeing for the company's employees and what values are their priority. Our complete wellbeing solutions focus on the mental and emotional aspects of workplace wellness programs. The training programs are designed to equip staff with essential skills to enhance well-being, interaction, morale and productivity.

In the process of transformation of the economy, serious changes (transformations) take place. They can influence not only one area of public life, but all at once: economic, political, social, spiritual. It is important to understand that people are simultaneously in different relationships with each other, they are connected with someone, they are isolated from someone when solving their life issues. Consequently, the spheres of public life are not geometric spaces in which different people live, they are relations between people, interconnected with various aspects of their life. Well-being is, perhaps, the very element that affects all spheres of public life at once.

For example, the nature of economic relations can influence the building of the social structure. A place in the social hierarchy forms certain political views, opens up appropriate access to education and other spiritual values. The economic relations themselves are determined by the country's legal system, which is very often formed on the basis of the spiritual culture of the people, its traditions in the field of religion and morality. The well-being of people is the main social value of any modern 
society [1]. After all, each of us wants to live a life that will be as full of positive events as possible, which will allow us to gain a sense of well-being. Its absence will negatively affect the state of human health, which means that it is necessary to look for funds that have contributed to improving the well-being of people. In this regard, scientists have developed an interest in the study of the concept of well-being and the study of the factors influencing this phenomenon.

To date, many studies have been carried out in various countries around the world, which have determined people's perception of "well-being." The results were varied. In some surveys, people characterized their own well-being as: good health, a sense of happiness and contentment, satisfaction with life, love of life, peace of mind, comfort, self-confidence, safety [2]. In other studies, well-being was defined as: a feeling of well-being, the ability to communicate with people, a sufficient amount of material benefits [3].

It turns out that at various stages of historical development, the influence of any sphere on a person is increasing. Of course, a person's values are formed on the basis of his environment. Therefore, different cultures have their own, different from others perception of well-being. Still, some components of well-being are of equal value to all countries.

1. Corporate well-being of organizations. The factors of well-being in society change over time. In the second half of the last century, the most important thing for a person was to feel security. Education and religion also played a special role in the life of society. Today the landmarks are completely opposite. For the British, for example, good mood and relaxation are in the first place, for Americans - career growth. The fact is that Americans and Europeans have different priorities: Europeans prefer to live a fulfilling life and enjoy it, while Americans are trying to realize the so-called "American Dream" and devote a lot of effort and attention to career growth. In other studies, scientists have found that happiness depends on material well-being: the higher a person's income and status, the more satisfied they are with their lives. Americans believe they can work hard in their careers, so they are happier when they work longer. Each hour worked brings them closer to achieving their goal. For Ukrainians, health and life satisfaction play an important role in shaping well-being (here we are as Europeans).

Despite the different descriptions of the feeling of a state of well-being by all respondents, it is clear that three main groups of indicators of people's well-being can be distinguished. In each group, there are various aspects of a person's life that affect his well-being, it combines many features of a person's attitude to himself and the world around him, they are also called a type of well-being [4].

Based on the survey, the researchers identify the following types: physical, social, material well-being. 
Physical well-being is a person's feeling that is characterized by good health. The World Health Organization characterizes health as a state of complete physical, mental and social well-being, and not just the absence of disease and physical defects.

There is another definition of the term "health". Health is a dynamic state or process of preserving and developing biological, physiological and mental functions, optimal working capacity and social activity with a maximum life expectancy (V.P. Kaznacheev). From the above definitions, we can conclude that the key to a good state of our body is the optimal functional and psychological state of a person.

The next type is social well-being. Social well-being is a type of well-being in which a person is satisfied with his social environment and contact with him, social status, and feels his security. The main thing in life for many people is family. Good relationships between loved ones are a factor that significantly affects a person's wellbeing. We often underestimate the impact of those close to us on our well-being. In addition to the support provided by loved ones, they allow you to gain a certain social status. If we start from the ideal idea, then each person should grow up in a fullfledged family (with dad and mom), and also create one of his own.

Another significant factor in social well-being is satisfaction with their professional activities. Most of us work in a traditional office environment, while others work in a factory, at home, or outdoors. Doing what you love is a person's ideal representation of what he should be doing throughout his life. Such work contributes to an additional interest in the quality of the task on the part of the individual.

The result in their field of activity will determine the well-being of a person. Safety is another important criterion for a person's social well-being. Each of us wants to live where there is no war, mass epidemics, murders and robberies. The confidence that nothing threatens you or your loved ones, allows you to find peace and get rid of unnecessary worries. Taken together, all of the above aspects affect the social well-being of a person.

The last type is material well-being. Material well-being is characterized by a person's satisfaction with the quantity and quality of material goods available to him. To meet his needs, a person needs to have certain financial capabilities. It can be noted that a person's worldview, values and environment play a role in the perception of the importance of wealth. Some people will be satisfied with the fact that they have a place to live and what to eat, while others will suffer from the fact that they cannot afford some expensive car.

A survey conducted in the UK showed that people associate their own wellbeing, primarily with their health and well-being. The importance of contact with family and friends was put in second place. Material well-being is not always included in the definition of well-being for older people in developed countries. 
The above assessment of the type of well-being is subjective, i.e. lists the criteria that people use to assess their own well-being. The well-being of the population should also be assessed according to objective indicators, since for example, it is extremely difficult to influence the interpersonal relations between people for the protection and restoration of monuments of national history.

It should be noted that interest in the problem of well-being increases in connection with the identification and study of objective and subjective criteria and factors of well-being, between which contradictions are very often found:

- firstly, social status and material well-being do not always coincide with the subjective well-being of the individual. This can be evidenced by the analysis of the results of studies of social well-being conducted in European countries (for example, analysis of the suicide rate in countries with a high level of economic development);

- secondly, under the influence of social changes taking place in society, subjective well-being changes, and this is not always associated only with economically beneficial transformations for the population. In this case, it is necessary to analyze how people's ideas about well-being in modern Ukraine are changing in comparison, for example, with the Soviet period;

- thirdly, social well-being in itself in different countries can be understood and perceived in different ways, regardless of the geographical, climatic and some other features of the territory.

Thus, the problem is expressed in the lack and inconsistency of knowledge about the criteria and factors of well-being, about the impact of social changes and social policy of the state on the subjective well-being of the individual and, ultimately, in the ratio of social and individual well-being. A high level of well-being contributes to the fact that people are willing to serve society, they can occupy positions in which they can benefit society, to establish contacts between groups and organizations. Initially, the role of such people may be small, but over time it can increase and more affect their environment.

In many ways, the success of any modern company depends on the efficiency of its employees. To achieve its main goal - maximum profit, the company needs to gather the most competent personnel in order to solve the most complex problems with them. Putting together a strong team is just a small step towards achieving the desired result. The interest on the part of the company is that the personnel do their job as efficiently as possible and use all their knowledge, skills and abilities for the good of the company.

In turn, the employee can bring the maximum benefit to the enterprise when he is interested in achieving the best result at his workplace. Employee motivation is an important part of employee success and includes many aspects. A high level of employee well-being is one of the important conditions for an employee to be 
motivated to achieve the success of his company, so managers need to look for tools that can improve the well-being of their employees.

A high level of personnel health, as mentioned above, is one of the main factors of well-being. As a rule, the majority of the working population fulfills their professional duties in conditions where their physical activity is limited, and outside work time, not everyone satisfies the need of their body for movement due to various reasons. This fact has a negative impact on human health. Poor health is mostly the result of a person's lifestyle.

The only effective means of replenishing the lack of physical activity of a person is physical culture and sports. Physical activity, in addition to satisfying the basic need, eliminates excess weight, normalizes the work of all systems and organs in the body, increases the efficiency and immunity of a person. Increasing the functional capacity of the body is the first step towards the formation of good health.

Physical culture and sports, as a rule, are considered as a means of physical improvement, but they also affect the psychological state of a person. Physical activity can reduce psycho-emotional stress and anxiety level, increase mental performance, improve mood, similar studies were carried out by such scientists as Wenberg R., Gould D., American researcher M. Sachs and many others.

The company, in order to increase the level of well-being of its own employees, can organize for them health-improving classes with various orientations, in which they will increase the functional and psychological readiness of their body. Carrying out various mass sports and sports and recreational activities, the purpose of which, first of all, will be to promote a healthy lifestyle among staff and their families. Such measures will create an idea of a healthy lifestyle and generate interest in physical education and sports. Also, such events will increase not only the physical well-being of the company's employees, but also social. Also, proper nutrition is the key to good health.

Most of us rarely monitor our diet, some simply have no idea about proper nutrition, while others, due to the lack of opportunity, get by with snacks in the form of fast food. In such cases, managers often organize a canteen on the territory of the enterprise or within walking distance from it, where employees could consume quality food.

In economically developed countries, personnel health management is seen as one of the methods to minimize labor costs and motivate employees. World practice shows that properly organized health management of employees allows to reduce the incidence of sickness in the team by $40-50 \%$, to reduce the number of days of disability by $20 \%$, to reduce the occurrence of chronic diseases by $10-15 \%$, to reduce the average period of temporary disability by $30 \%$, by $20 \%$ - to increase labor productivity [5]. 
You can create social well-being among your own employees by creating a friendly team, where employees get along well with each other both in formal and informal settings, as well as by providing career opportunities. Team building is one of the most challenging management tasks to accomplish. The unity of the team helps to combine efforts to solve the problems of the organization, and also not to create an environment in which some employees will purposefully interfere with the performance of their duties by others. To form a friendly team, it is necessary to clearly distribute responsibilities between employees and outline the rules to which all employees, without exception, must obey. They will help prevent some conflicts, and some to solve. Another means for uniting the team is the organization by the company of various holidays (New Year, Christmas, etc.), cultural, sports and recreational and sports events. Such measures allow to unite the team, create friendly relations between employees.

Career growth is one of the important components of human well-being. Each of us sets certain goals in life that he is trying to achieve, including those associated with achieving success in his professional field. For an employee, in addition to a good salary, the social status that he possesses is important, as well as the possibility of raising it. An enterprise in which there is an opportunity for career growth receives in return highly motivated personnel who have it as a specialist, and they, in turn, get the opportunity to realize themselves in the professional sphere. Thus, employees have achieved their goals in their professional activities, which is an important factor in achieving a sense of human well-being.

The company directly affects the material well-being of its employee. Salary is the main means of achieving material well-being for an employee. A person's financial capabilities depend on his ability to acquire the material wealth he needs. If his salary is higher than the average one received by employees of other firms working in the same position, then this will significantly increase his material wellbeing.

Another means of increasing the material well-being of an employee is the help from the company to its employees in the acquisition of expensive material goods. After all, the assessment of one's own well-being depends on the quality and quantity of material wealth, the ability to spend your vacation abroad, living conditions, the availability of vehicles and its class. Meeting such needs will certainly enhance the employee's well-being.

Few companies today try to improve the well-being of their own employees. By increasing the well-being of their staff, the manager receives in return highly motivated employees who are able to work for the good of their organization. Creating employee well-being can help retain high-value employees beyond retirement age. This will help transfer experience to younger staff and help the 
company stay in leadership positions. Also, the desire to work at this enterprise appears among other persons who have nothing to do with this company, which means that the director has the opportunity to select the most competent personnel.

Leaders of large companies are actively studying modern methods of company management, and are also trying to create new ones that will help to use their own resources even more efficiently. The potential for increasing the competitiveness of a company lies in its employees, whose effective management will allow it to gain a competitive advantage over other market participants. Corporate culture is an effective method of managing its employees, which is responsible for the motivation, development of personnel, the correctness of work performance, the relationship between employees, etc.

\section{Key aspects of assessing the success of corporate well-being programs.} The role of the enterprise culture is difficult to overestimate, its main goal is to increase the efficiency of all employees, and therefore the overall activity of the company. Hence, we can conclude that the corporate culture of any enterprise is primarily aimed at employees, it creates the necessary working conditions in which the company's personnel can perform their work with maximum efficiency.

The first important step a company culture takes is team building or recruiting. An important guarantee of the company's successful activity is competent personnel; in order to attract such employees, it is necessary to interest them in working conditions. In such cases, a person will give preference to the enterprise that is more capable of satisfying his needs. When a certain number of needs are satisfied, human well-being will necessarily increase.

Employee motivation is an important part of working with the company's personnel. A motivated and competent employee is able to bring maximum value to his organization, but his motivation depends on many factors. One of the ways to influence the employee's motivation is to promise to reward for completing the assigned task. Maximum motivation for success will be that reward that will bring him maximum satisfaction, thereby increasing his sense of well-being.

An important task of corporate culture is to create a favorable working atmosphere within the work collective. First of all, the culture of the corporation is created in order to improve the interaction and relationships between the personnel of the enterprise. The atmosphere in the work collective is an important component, both for the successful operation of the enterprise.

A large number of conflicts, poor relationships with colleagues - this is what affects the overall state of the company. It is the culture of the corporation that can prevent or resolve such situations. Many decisions are made on the basis of the rules that have been adopted by the team, and each member of the organization must 
adhere to them, they help to reduce the number of conflict situations, and any such precedent will be resolved fairly based on generally accepted norms.

The attitude towards newcomers, their adaptation to the conditions and the team of the company is also part of the development of the corporate culture of the company. Mastering a new team is stressful for any person. One of the tasks of the corporate culture is to ensure the painless infusion of new employees into the team, so that this is not a problem, both for old-timers of the company and for newcomers. Such measures will help maintain a favorable climate in the team.

Good relationships with colleagues is an important factor in a person's wellbeing. We spend most of our working life at the workplace, which means that we are in contact with the staff of our company for a significant amount of time. Good relationships with colleagues at work contribute to an increase in social well-being, since it directly depends on the degree of satisfaction with contact with people around.

The corporate culture is also responsible for organizing various sports, cultural, recreational events and holidays that help create a friendly atmosphere in the team. Communication in an informal setting will allow you to find common interests with your colleagues, make friends and communicate with families. This will help a person expand his social circle, find new friends among the work collective, which will also increase social well-being. As part of various sports and recreational activities, a healthy lifestyle is promoted among the work collective. Such measures will contribute to improving the level of health, which is an important component of human well-being. Another of the tasks of an organization's culture is to unleash the potential of its employees. First, comfortable working conditions in which he directly performs his professional duties. Secondly, the ability to propose changes in the company's work in the market.

The proposed ideas will combine the accumulated knowledge and experience, and in the case of the implementation of the conceived ideas in life, it will allow the employee to evaluate their correctness and realize himself as a specialist in his field. It is professional implementation that is a factor in increasing human social wellbeing.

The corporate culture is aimed at creating a favorable working environment for its employees. It is created and developed by management in order to demonstrate to their staff how valuable they are in the company's activities. The personnel policy of an organization directly affects the welfare of its employees. It is an important tool for the development and competitiveness of the company. Corporate culture is a part of the personnel policy that creates a favorable environment within the enterprise.

The culture of the organization reflects the value orientations of the enterprise, which include the attitude of management towards its employees, it is aimed at 
improving the working conditions of the company's employees. The developed culture of the organization has a positive effect on the well-being of its employees, who, in a comfortable working environment for themselves, can at the maximum benefit to their company, while enjoying their activities.

In the period from 10.07.2019 to 16.07.2020, a sociological survey was conducted using the method of questioning the employees of the Prykarpattyaoblenergo joint-stock company (an energy company that distributes electricity to consumers). The company has a salary that is indexed annually in accordance with inflation. In addition, the employee is entitled to a bonus for meeting the indicators of the production and economic activity of the enterprise for the month. Newly hired employees undergo a primary medical examination at the expense of the enterprise, as well as a periodic one after a year of work. It is important that in addition to the standard set of services under the compulsory health insurance policy, each employee has the opportunity to use the services of supplementary health insurance in any medical institution with which an appropriate contract has been concluded. Of great importance in the company's activities are charity and sponsorship activities, various actions in support of culture, science and education, physical education and sports, promotion of a healthy lifestyle.

Based on the stated goal of the survey, the following tasks can be distinguished:

1. Determine what well-being means for employees today.

2. To reveal the dependence of job and life satisfaction on the labor values of the company's employees.

3. Establish what is of value to the respondents.

The survey was conducted anonymously and included 12 questions, 9 of which were in a closed form and 3 in an open form. The total number of respondents was 350 people, of which $46.4 \%$ were males and $53.6 \%$ were females. The survey involved respondents with an average age of 41 years.

The largest proportion of respondents were women aged 44 to 47 years. All interviewed employees have higher education. $38.5 \%$ have been working for the company for over 10 years. The questionnaire included questions directly related to labor values. The concept of labor values does not include the characteristics of the employee's workplace. They reflect general judgments about the work, ideas about the desired.

Thus, 53.6\% of respondents believe that the level of workload at work is within the normal range (satisfactory), $37.3 \%$ of respondents experience high workload at the workplace, $6 \%$ of employees could take on additional workload, and $3.1 \%$ of respondents rate the level of workload at work "in different ways".

The next 2 questions relate to the psychological atmosphere in the team and the impact of various corporate events held in the company. The majority of respondents, 
namely $65.3 \%$, "quite normally" assess the psychological atmosphere in the company, $19.9 \%$ of employees believe that the atmosphere is comfortable, even contributes to productivity at work. Slightly less, $14.8 \%$ of respondents, criticize the climate in the company, considering it unfavorable.

The social policy of Prykarpattyaoblenergo JSC provides for the implementation of a set of measures aimed at increasing the level of life support and efficiency of personnel. In this regard, a question was drawn up about the attitude of employees to the events held in the company. $68.4 \%$ of employees support the social policy of the organization and believe that corporate events unite the team. $25.3 \%$ try to take an active part in all kinds of cultural festivals and events. $6.3 \%$ of the respondents only occasionally attend events. It should be noted that none of the respondents indicated a negative attitude towards the company's social policy. Some indicated at once 2 answer options associated with a positive attitude towards events and taking an active part in them.

The position held, the status of the employee in the organization, priority areas in work are factors that directly affect employee satisfaction. They influence the overall assessment of life satisfaction in some way, although the degree of such influence may differ for different workers and professional groups. The survey has shown that $60.9 \%$ of employees are absolutely satisfied with their position, $31.1 \%$ would like to achieve a promotion, and only $8 \%$ are not satisfied with their position, and would not like to be promoted up the ladder.

To the question "what is more priority for you in your work" 5 variants of answer were offered. Many employees chose several options at once. Thus, it turned out that $79.7 \%$ of respondents give first place to wages, slightly fewer $(64.5 \%)$ employees value direct interest in work in work, $35.6 \%$ of respondents chose the opportunity for career growth. Surprising is the fact that employees value the social aspect of work more than the prestige of the organization $(26.2 \%$ and $22.1 \%$, respectively).

One of the main objectives of the study is to find out what meaning society gives to the concept of "well-being", from which components a person forms his subjective well-being. It was found that for the majority of respondents, well-being is family $(79.1 \%)$, satisfaction with life $(74.6 \%)$, health (70.3\%). The income level is also high for the respondents $-55.4 \%$. Safety plays an important role in the life of $40.1 \%$ of respondents. Feeling meaning and purpose in life is important for $35.3 \%$ of people. $31.2 \%$ of respondents include social status in the concept of well-being. Religion and spirituality affect subjective well-being in $6.2 \%$ and $18.1 \%$ of respondents, respectively.

The last 2 questions of the questionnaire were presented in an open form. Company employees answered what, in their subjective opinion, had lost value in life 
over the past 5 (10) years, and what they began to value more. Of all 350 respondents, 91 did not answer the proposed questions. In this regard, further results of the study were based on the opinions of 259 respondents. Since the questions were asked in an open manner, the respondents gave a variety of answers. But many of the answers quite often converged. For example, for $26 \%$ of respondents over the past 5 (10) years, the opinions of other people have ceased to be of value. Many of them indicated that the opinions of loved ones (family, friends) still remain meaningful to them. Social status, material wealth, income and career are of no value for $26 \%$ of the respondents.

$19.1 \%$ of employees indicated that various kinds of holidays (parties) and the use of alcoholic beverages are not so important in their lives. There were also those for whom "nothing" has ceased to be of value $-11.5 \%$ of the respondents. These are the most common answers from company employees. Among others, there were obligations, plans for the future, negative attitude.

If we talk about human values, which people began to attach more importance to, then it can be noted that many respondents began to value several components in life at once. A large preponderance here goes towards health: $53 \%$ of respondents began to value their health and the health of their loved ones over the past 5 (10) years. Time is the second most important value for the surveyed company employees (37\%). They indicated both free time and time spent with family, loved ones and friends. And $18 \%$ of respondents began to value their family more. The following components were also listed: freedom of choice, spiritual development, work, decency.

Summing up, we can say that today scientists are actively studying the issues of human well-being. This topic is very relevant, and also concerns absolutely everyone on our planet. All types of well-being are closely interrelated, and an increase in one of them will affect the well-being of the person as a whole. The search for universal means of improving well-being is the end result of successful research into this phenomenon. Improving employee well-being is an important part of a successful firm.

Analyzing the data obtained and summarizing the entire sociological study, it should be borne in mind that middle-aged workers took part in this survey. These are people who have already developed priorities in life, they "stand firmly on their feet", have life experience and value guidelines.

The employees assessed their "real" position in the company. By answering the questionnaire, they thereby expressed general judgments about the work and ideas about what they wanted. It's about labor values. Labor values can act as a special personal resource that contributes to the effective functioning of the individual and, ultimately, leading to an increase in satisfaction with various aspects of work and life. 
The results of the study showed that the level of workload at work corresponds to the position held. Employees are ready to cope with a large volume of work with decent wages. At the same time, employees assess the psychological atmosphere, which is an important (and sometimes decisive) factor in the company, as favorable.

Despite the fact that $79.7 \%$ of employees put wages first in their work, they do not represent value in life for them. None of the company's employees indicated income as the main component when answering the question "what did you value more". On the contrary, material wealth and income have lost value for them in recent years.

However, half of the workers still classified the level of income as one of the components of well-being. It was found that socioeconomic status for employees has little effect on subjective well-being. Most employees prioritize their values and the health of their loved ones. Well-being for them is family, life satisfaction, health. Social status and income level are paramount for only a few people. The results show that although the pursuit of social status is one of the leading human motivations, achieving high status does not guarantee happiness. The so-called sociometric status, respect and admiration of the immediate environment (for example, among friends or colleagues), has a much stronger effect on the level of subjective well-being, life satisfaction than socioeconomic. Unlike money and material goods, respect, relationships and mutual understanding in the family are sustainable and long-term well-being.

The mentality of a Ukrainian person is formed in such a way that career growth and material wealth do not make him happy. Religion and spiritual development over the past decades for a person no longer occupy a leading position.

Unchanged, both for Ukraine and for foreign countries, according to the results of sociological surveys, it turned out that people highly value life surrounded by their family and friends. The support and love of close people creates for a person a sense of need in life. The family is the first social school of relations with people and a personal microenvironment for personality development. For children, a family is practically the whole world. Family values and traditions in the first years of their life are the main source of knowledge not only about the physical world, but also about the world of feelings. Everything that a child learns in his family becomes the basis of his worldview already in adulthood. Therefore, the family for most people is in the first place among the components of well-being.

\section{References:}

1. Beaumont, J. (2013), Measuring National Well-being - Older people and loneliness. URL: http://www.ons.gov.uk/ons/dcp171766_304939.pdf.

2. Tompson, A. and Striklend, A. (2003), Strategic Management: Concepts and situation analysis. Kyiv, Ukraine.

3. Estinne, M. (1997), "An organizational culture compatible with employability", Industrial and Commercial Training, vol. 29, №6, pp. 194-199. 
4. Holostova, E. I. (2014), Socialnaya rabota i socialnaya splochennost obshchestva [Social work and social breadth of society], Dashkov i K., Moscow, Russia, 127 p.

5. Konovalova, V. (2010), “Staff health - an employer's headache?”, Kadrovyk. Kadrovii menedzhment, № 11. URL : http://hr-portal.ru/article/zdorove-personalagolovnaya-bol-rabotodatelya. 